DOI: http://dx.doi.org/10.11606/issn.1984-4867.v27i2p454-468

\title{
Narrativa Cinematográfica: um dos mundos possíveis para adentrar o universo conceitual da hospitalidade
}

\author{
A Cinematic Narrative: one of the possible worlds to enter the conceptual universe of the \\ hospitality
}

\section{Narrativa Cinematográfica: uno de los mundos posibles para adentrar al universo conceptual de la hospitalidad}

Marcia Maria Cappellano dos Santos ${ }^{1}$

Thays de Oliveira Marcelino ${ }^{2}$

José Carlos Köche ${ }^{3}$

\section{Resumo}

Este texto aborda o universo pragmático e teórico da relação de hospitalidade vivenciada na trama ficcional do filme $O$ Conto Chinês. A partir de referenciais conceituais contemporâneos sobre semântica ficcional e do conceito de diegese utilizados na análise fílmica, divergentes da concepção platônica e aristotélica de mimese, é retomada a trama e o universo narrativos do filme para refletir sobre vários aspectos da hospitalidade vivenciados entre o hospedeiro e o hóspede nessa obra de ficção. Recorre-se, nessa direção, a conceitos tais como hospitalidade condicional, tolerância, acolhida limitada, concessão condescendente, bidimensionalidade e sociodinâmica do acolhimento. À guisa de considerações finais, a análise fílmica transita para o mundo real, destacando a importância do sentido do encontro das subjetividades diferentes, mas não indiferentes, como também do sentido de querer e festejar esse encontro.

Palavras-chave: Hospitalidade; Narrativa cinematográfica; Mimese e diegese; Análise fílmica; Mundos possíveis e existentes reais.

\section{Abstract}

This text discusses the pragmatic and theoretical universe of the hospitality relationship experienced in the fictional plot of the film A Chinese Tale. From contemporary conceptual references about fictional semantics and from the diegesis concept used in the film analysis,

\footnotetext{
${ }^{1}$ Doutora em Educação pela Universidade Federal de São Carlos (UFSCAR). Bacharel e Licenciada em Letras pela Universidade Presbiteriana Mackenzie (MACK). Coordenadora, Docente e Pesquisadora do Programa de Pós-Graduação em Turismo e Hospitalidade - Mestrado e Doutorado, da Universidade de Caxias do Sul (UCS). Caxias do Sul, Rio Grande do Sul, Brasil. E-mail: mcsantos@ucs.br

2 Mestranda do Programa de Pós-Graduação em Turismo e Hospitalidade - Mestrado e Doutorado da Universidade de Caxias do Sul (UCS). Licenciada em Turismo pela Universidade Federal Rural do Rio de Janeiro (UFRRJ). Caxias do Sul, Rio Grande do Sul, Brasil. E-mail: thaysmarcelino@yahoo.com.br

${ }^{3}$ Doutor em Filosofia pela Pontifícia Universidade de Salamanca, Espanha (UPSA). Licenciado em Filosofia pela Universidade de Caxias do Sul (UCS). Professor e Pesquisador do Programa de Pós-Graduação em Turismo e Hospitalidade - Mestrado e Doutorado da Universidade de Caxias do Sul, (UCS). Caxias do Sul, Rio Grande do Sul, Brasil. E-mail: jckoche@ucs.br
} 
which are divergent from the Platonic and Aristotelian concept of mimesis, the plot and the narrative universe of the film is resumed to reflect on various aspects of the hospitality experienced between the host and the guest in this work of fiction, such as conditional hospitality, tolerance, limited welcoming, condescending concession, two-dimensionality and socio dynamics of the welcoming. It concludes by referring to the real world, highlighting the importance of the sense of the meeting of different subjectivities, yet not indifferent ones, as well as the sense of wanting and celebrating this meeting.

Keywords: Hospitality; Cinematic narrative; Mimesis and diegesis; Film analysis; Possible and real existing worlds.

\section{Resumen}

Este texto aborda el universo pragmático y teórico de la relación de hospitalidad vivenciada en la trama ficcional de la película El Cuento Chino. A partir de referenciales conceptuales contemporáneos sobre semántica ficcional y del concepto de diégesis utilizados en el análisis de la película, divergentes de la concepción platónica y aristotélica demimesis, es retomada la trama y el universo narrativos de la película para reflexionar sobre varios aspectos de la hospitalidad vivenciados entre el hospedero y el huésped en esa obra de ficción, tales como hospitalidad condicional, tolerancia, acogida limitada, concesión condescendiente, bidimensionalidad y socio dinámica de la acogida. Concluye, reportándose al mundo real, destacando la importancia del sentido del encuentro de las subjetividades diferentes, pero no indiferentes, como también del sentido de querer y festejar ese encuentro.

Palabras clave: Hospitalidad; Narrativa cinematográfica; Mimesis y diégesis; Análisis de la película; Mundos posibles y existentes reales.

\section{Introdução}

Dados dos sentidos, dados da ciência, percepção, razão, linguagem, empiria, sujeito, objeto, teoria, subjetividade, objetividade, intersubjetividade, neutralidade, verdade, singular, universal, são todos, entre outros, termos cuja base conceitual - em sua diversidade, conforme os supostos teóricos que lhe estão subjacentes - orbitam em torno do conceito de realidade e das formas e possibilidades de acesso ao real. Esse universo faz-se ainda mais instigador quando nele está inserido o termo "ficção" e, igualmente, os que em torno dele podem orbitar, como: significado, significação, sentido, signo, representação, imitação, expressão, diegese, mimese, constituindo-se uma trama cuja tessitura traz à reflexão o status ontológico dos "mundos" em relação. 


\section{Conceitos de Referência}

Particularmente quando aportamos no mundo ficcional, nas teorizações historicamente construídas sobre relações miméticas entre ficção e realidade, remontamos a Platão e a Aristóteles, respectivamente em A República (Livro X) e na Poética. Na perspectiva de ambos, a ficção deriva da realidade. Têm-se representações, imitações de objetos cuja existência independe da cognição.

Para Platão, a mimese praticada pelo poeta não filósofo seria um simulacro, uma cópia das aparências, distanciada das essências do mundo, ou das ideias. "A imitação está longe da verdade e, se modela todos os objetos, é porque respeita apenas a uma pequena parte de cada um, a qual, por seu lado, não passa de uma sombra.” (PLATÃO, s.d, p. 267). Já para Aristóteles, a mimese, que tem por objeto a práxis humana, implica a produção de semelhanças em qualquer âmbito da criação artística. De um lado, a verossimilhança criada pelo poeta possui, como propriedade necessária, a referência externa da realidade representada; de outro, o verossímil, que institui o possível e não o verdadeiro, abre espaço à ficção deliberada e dele decorrem relações de aprendizagem moral como uma das funções políticas da mimese (JEHA, 1993). Referindo-se à tragédia, Aristóteles (1974, p. 14) afirma que se trata de "[...] imitação, não de pessoas, mas de uma ação, de uma vida, e a felicidade e a infelicidade estão na ação, e o fim é uma ação, não uma qualidade" (Tradução nossa).

Um avanço no tempo chegando, de modo especial ao século $\mathrm{XX}$, conduz a leituras críticas das tradicionais relações miméticas, vindo pôr em questão a relação representacional biunívoca entre o particular real e o particular ficcional, a representação dos universais reais por particulares ficcionais, ou uma fonte real (o autor) representando um particular ficcional (DOLEZEL, 1988 apud JEHA, 1993). Para o teórico da literatura, essa práxis crítica, conforme destaca Jeha (1993), repousa no fato de as ficções, mesmo as mais fantásticas, serem interpretadas referindo-se a um único universo de discurso, ou seja, o mundo real. Assim, referentemente à criação literária, a proposição é a de "[...] uma semântica ficcional definida de acordo com um modelo de múltiplos mundos possíveis" (JEHA, 1993, p. 84).

Independentemente, pois, das teorizações historicamente construídas a partir das quais relações miméticas entre ficção e realidade são vistas como especulares, referenciais, icônicas, indexais, entre outros olhares, tem-se a tese, com Dolezel, de que mundos ficcionais são possíveis estados das coisas, sendo assim legitimados todos os possíveis não-realizados 
(indivíduos, atributos, acontecimentos), protegendo a identidade dos indivíduos ficcionais. E dada essa condição, todas as entidades ficcionais passam a ser ontologicamente homogêneas requisito necessário para a coexistência e copossibilidade de particulares ficcionais (DOLEZEL, 1988 apud JEHA, 1993). "O conjunto de mundos ficcionais é ilimitado e maximamente variado. Ao interpretarmos os mundos ficcionais como mundos possíveis, libertamos a literatura da tarefa de imitar servilmente o mundo real" (JEHA, 1993, p. 85). Por outro lado, é possível alcançar os mundos ficcionais, transpondo-se barreiras entre os mundos, realizando, por canais semiósicos ${ }^{4}$, o trânsito dos existentes reais para o mundo dos possíveis.

O material que o mundo real fornece tem que sofrer uma transformação para ser admitido no mundo ficcional: ele deve ser convertido em possíveis nãoreais, com todas as consequências lógicas, ontológicas e semânticas. Essa conversão ocorre através da semiose textual e porque, para o signo, é indiferente se o objeto a que ele se refere é também uma coisa ou se existe apenas na imaginação. ${ }^{5}$

Graças aos canais semiósicos e a essa propriedade do signo, o leitor real entra em mundos possíveis e deles se apropria como fonte de experiência, da mesma maneira como ele integra e experimenta o mundo real. (JEHA, 1993, p. 85-86).

É, pois, através do agenciamento humano que esses mundos são construídos e permeados.

Tendo como objeto de estudo o que denomina "signo dramático", Brizuela (2000, p. 3), enfatiza a presença do teatro na construção ficcional, ao propor que é particularmente ali que o signo alcança todas as possibilidades de criação de sentido, uma vez que a representação cênica se dá com palavras e objetos que se semiotizam, ao serem "[...] utilizados por sujeitos tanto em nível intradiegético (relações entre personagens) e extradiegético (relações entre personagens e público espectador)"

\footnotetext{
${ }^{4}$ Segundo Brizuela (2000, p. 2), em todo processo semiósico, sujeitos e signo se relacionam de modo dinâmico. "Os sujeitos se manifestam como condutas humanas criadoras de sentido, e o signo - enquanto produto do processo -, como a unidade de sentido nesse uso. [...] A atividade semiósica dos sujeitos tem duas possibilidades: a) relacionar forma e sentido a partir de um signo que procede de um sistema já normatizado, prévio ao uso; b) estabelecer uma relação que não está previamente fixada em um sistema. [...] Nesse caso, o sujeito cria um signo em função da relação que estabeleceu. Esta última é a atividade semiósica literária e, por conseguinte, teatral, na qual o signo se manifesta com uma notável mobilidade e podem criar-se tantas interpretações quantos forem os sujeitos a atribuir-lhes sentido." (Tradução nossa).

${ }^{5}$ Considerados o objetivo e limitações destas considerações introdutórias, não são aqui analisados pressupostos teórico-conceituais do termo "signo" concernente quer à abordagem semiológica, quer à abordagem semiótica, empregados, no âmbito da literatura, do teatro ou da narrativa cinematográfica, pelos autores em referência. Fica subjacente, no entanto, o entendimento do signo não como "um objeto com determinadas propriedades, mas como uma relação ou uma função." (EPSTEIN, I., 1990, p. 29).

${ }^{6}$ A diegese diz respeito à dimensão ficcional da narrativa. A origem do termo é associada a Platão, em A República (Livro III), na contraposição entre a narrativa de ações pelo poeta (Homero) assumindo sua identidade (diegese) e a narrativa com imitação (Homero falando como o próprio Crises) - como se não fosse o poeta (mimese).
} 
Reportando-se ao entendimento de Bogatyrev (1971), a autora assinala que os signos no teatro manifestam-se direta ou indiretamente nos cenários. Os diretos compreendem os signos de objeto (que designam o que mostram); os indiretos, os signos de signo (que evocam algo além do que designam e têm valor conotativo) e os símbolos (que representam algo em razão de uma correspondência analógica).

Passando do mundo ficcional no texto literário e no teatro para a narrativa cinematográfica, encontra-se em Aumont e Marie (1988, p. 88), referentes conceituais para a análise fílmica, com suas possibilidades de abordagem. Para os autores, o filme consiste em uma obra “[...] artística autônoma, suscetível de gerar um texto (análise textual) que ancora suas significações sobre estruturas narrativas (análise narrativa), sobre aspectos visuais e sonoros (análise icônica), e que produz um efeito particular sobre o espectador (análise psico-analítica)" (Tradução nossa).

A análise remeteria ainda ao conceito de diegese, para o que se pode recorrer a Philippe Sohel, em sua obra Images du récit (2007), na qual refere estudos fílmicos de Etienne Souriau (La structure de l'univers filmique et le vocabulaire de la filmologie, 1948,1953), de Gérard Genette (Nouveau discours du récit, 1984) entre outros autores. Sohel (2007) traz o entendimento desses de que a diegese não se confunde com a sequência de ações de um relato: ela é o universo que permite essa história, ou no qual ela se desenvolve, com sua própria verossimilhança, suas próprias regras. Nessa mesma direção, reporta-se a André Gardies, (Le récit filmique), para quem a diegese designa um “[...] mundo, um universo espaço temporal, coerente, povoado de objetos e de indivíduos possuindo suas próprias leis (semelhantes eventualmente às do mundo da experiência vivida)" (GARDIES, 1993, p.137 apud SOHEL, 2007, p. 18, tradução nossa) - mundo esse dado e representado pelo filme, mas cuja construção se faz pela atividade mental e pelo imaginário do espectador.

Tendo presente essas considerações - que, por sua incompletude em abrangência e aprofundamento, devem ser lidas apenas como de caráter introdutório -, será no trânsito entre ficção, mundo possível, particulares e universais ficcionais e reais, semiotizações e universo narrativo, que se situarão as reflexões aqui pretendidas sobre o filme $O$ Conto Chinê $^{7}$, cuja trama narrativa - pontuada apenas por alguns fragmentos que ficaram registrados de modo especial na memória - permite-nos múltiplas "re"-construções e agenciamentos

\footnotetext{
${ }^{7}$ Com o título original Um conto chino, o filme, argentino, sob a direção de Sebastián Borensztein, data de 2011.
} 
interpretativos de "possíveis estados das coisas", conduzindo-nos a adentrar o universo pragmático e teórico das relações de hospitalidade, foco temático desta análise fílmica.

As primeiras incursões reflexivas sobre $O$ Conto Chinês nos fazem de imediato perguntar o que faríamos se, de repente, por um evento do acaso, nos víssemos impelidos a acolher em nossa casa um estranho e com ele ter de passar a conviver diariamente, sendo que um desconhece totalmente o idioma do outro. E ainda mais: com idiomas profundamente diversos e histórias de vida, culturas, expectativas/necessidades e disposições absolutamente distintas. Assim é que o espectador é chamado a adentrar o universo da ficção, a enredar-se na trama narrativa tecida no entrelaçar do verossímil, do possível, do real.

\section{A Trama e o Universo Narrativos: o filme}

Roberto, um veterano da Guerra das Malvinas, que vivia recluso em sua rotina (na loja de ferragens - da qual é o proprietário - e em sua casa), é compulsivamente metódico, avesso a inovações e colecionador de notícias jornalísticas trágicas e insólitas, que, a seu ver, confirmavam que a vida não apresentava sentido.

Sem desejar/permitir invasão em seu mundo interior, presencia, ocasionalmente, o momento em que, um chinês (Jun Hio Qian) que viera a Buenos Aires à procura de um único parente que lhe restara, é assaltado por um motorista de táxi que o atira para fora do veículo. "Falando" cada um em sua língua, Roberto leva o chinês para sua casa, desencadeando-se, a partir daí, uma sequência de tentativas de localizar o referido parente, para o que busca auxílio da Embaixada e de eventual tradutor no bairro chinês - caminhos que não surtem efeitos. $\mathrm{O}$ comerciante, mesmo estipulando-se o prazo de uma semana para solucionar aquilo que se constituía em um problema a resolver, vê-se forçado a abrir um espaço no ambiente que era só seu, oferecendo-lhe comida (dividindo sua austera refeição) e um lugar para dormir. Enquanto aguardam manifestação da Embaixada, Jun Hio Qian, em contrapartida, reorganiza os fundos da loja e, posteriormente, o quarto que lhe fora destinado.

Essa nova rotina é rompida, contudo, em função de um incidente em que o jovem acaba destruindo objetos que remetiam à memória da mãe do comerciante, que falecera após seu nascimento, com os quais a mantinha "presente" em sua vida. O chinês é expulso da casa e deixado num táxi com a recomendação de Roberto de levá-lo ao bairro chinês, livrando-se assim do que lhe parecia um pesadelo. Todavia, ao ouvir comentário de uma amiga (que dele 
estava enamorada sem encontrar, porém, uma abertura relacional que permitisse um envolvimento amoroso) sobre como seria estar em outro país vivendo situação semelhante à do chinês e encontrar alguém generoso como ele, Roberto, por um instante, reflete sobre os acontecimentos vividos até então, sobre a verdade dessa "generosidade" e, movido por um aparente remorso, vai em busca do rapaz que o encontra sendo agredido fisicamente por um desafeto e o salva, voltando ambos para casa e, dessa forma, retomando o processo de convivência, que, aos poucos vai assumindo uma outra perspectiva relacional.

Fortuitamente, Roberto depara-se com um entregador de comida chinesa, falante do idioma chinês, possibilitando, pela primeira vez, uma comunicação verbal entre eles mediada pela tradução. Frente a frente, compartilhando o jantar - desta feita, comida chinesa no lugar do tradicional prato da cultura local, que se repetia todos os dias - ambos dividem suas histórias marcadas por acontecimentos trágicos: de um lado, além da perda da mãe, a morte do pai de Roberto enquanto estava na guerra; de outro, a perda da noiva em um acidente provocado por um animal que, desastradamente, por um problema causado no compartimento de carga de um avião, é lançado ao mar, atingindo a embarcação em que se encontravam. Esse fato incomum e inusitado encontra-se casualmente entre os recortes de notícias colecionadas por Roberto, estabelecendo-se assim um vínculo de outra natureza entre eles.

Recebida da Embaixada a notícia de que o parente de Jun Hio Qian havia sido encontrado, o chinês, profundamente agradecido, despede-se de Roberto, deixando, na parede dos fundos da loja, como uma lembrança em forma de arte, a pintura do animal que estabelecera uma conexão em suas vidas e com a da amiga, a qual havia se mudado para uma fazenda. Esse acaba sendo um ponto-chave para que Roberto se permita aflorar suas emoções, indo ao encontro da moça.

\section{Refletindo sobre Hospitalidade}

Mais do que mera sequência de fatos, o universo diegético e sígnico em que se desenrola a narrativa remete de imediato a tomar emprestados, denotativa e conotativamente, dizeres de Montandon (2011), para quem tudo começa à soleira da porta à qual se bate e que se abre para um rosto desconhecido, para um estranho, estabelecendo-se uma situação de proxêmica, de vulnerabilidade e de propriedade, na medida em que se dá a invasão de um território constituído, delimitado e povoado por uma história de vida pessoal, no qual o outro aparece 
como um intruso. A entrada do chinês, que sobrevém de forma inesperada na vida do comerciante, desestabiliza barreiras e distanciamentos físicos e psicoafetivos fortemente estabelecidos ao longo do tempo, do que tende a emergir a hostilidade latente de todo ato de hospitalidade.

Nessa “[...] experiência de sentir-se social e pessoalmente 'invadido' [estaria presente] a convicção de que pertencer a um lugar é ter direitos sobre este" (PERAZZOLO et al., 2015, p. 59). No entendimento de Baptista (2005, p. 16), "A entrada de outrem representa sempre a invasão de um espaço e a interrupção de uma rotina" Nesse sentido, poder-se-ia dizer que, ao permitir ao estranho transpor a soleira da porta e adentrar seu espaço, o anfitrião estaria assumindo para si o sacrifício próprio à dádiva (CAMARGO, 2006). Identifica-se assim a condição interior conflituosa do comerciante em atender ao que seria um "dever ético-moral", em ceder à imposição da "dádiva" e, ao mesmo tempo, em resguardar sua identidade, ou mesmidade, no pertencimento a "seu" território.

Essa não disposição para o vínculo propicia o desencadeamento de um “[...] ciclo, negativo e antagônico, marcado pela crença de que o estrangeiro nada traz: ao contrário, tira, ativando um ciclo hostil, a inospitalidade na sua forma mais primária" (PERAZZOLO et al., 2015, p. 60). A hospitalidade aí se “[...] apresenta como uma ponte frágil e perigosa estabelecida entre dois mundos: o exterior e o interior, o fora e o dentro" (GRASSI, 2004, p. 45).

Essa condição parece simbólica e paradoxalmente fazer-se representar por elementos ou ações cuja natureza, primariamente aproximativa, cede lugar à configuração/instituição de anteparos (signos de signo, na tipologia de Bogatyrev, antes referida) demarcativos de territórios. Dentre eles, por exemplo, a mesa em que fazem as refeições, a qual, no entanto, os mantém em lados diferentes, opostos, reiterando o silêncio mútuo. Igualmente, poderia ser citado o balcão de atendimento na loja, apoio físico para a efetivação das interações comerciais, do qual o chinês é mantido afastado, assim como o chaveamento, pelo comerciante, da porta do quarto, contíguo à sala, que lhe é destinado para dormir.

Estariam aí configurados os limites entre hospitalidade e tolerância, ou, como destaca Derrida (2001, apud BORRADORI, 2003), estaria aí configurada uma acolhida limitada, vigilante do que considero "meu" território, "minha" casa, "minha" língua. Em outras palavras: uma hospitalidade condicional. Mesmo entendendo ser preferível demonstrações de tolerância a demonstrações de intolerância, o filósofo vê com reservas a tolerância e o discurso que ela 
organiza. "É um discurso com raízes religiosas; mais freqüentemente (sic) [...] usado do lado dos que detêm poder, sempre como uma espécie de concessão condescendente" (DERRIDA, 2001 apud BORRADORI, 2003, p. 137).

De outra parte, numa analogia a um fragmento de análise da hospitalidade no universo homérico da Odisseia, estariam também sendo desenhadas/demarcadas, no espaço-tempo da narrativa fílmica, fronteiras e identidades, entre "[...] o 'ir além' e penetrar em terra ignota" [na perspectiva daquele que está sendo recebido - o chinês], e o '[...] receber o 'outro', estrangeiro/hóspede, com seus costumes diversos" [na perspectiva do hospedeiro, o comerciante] (SELIGMANN-SILVA, 2005, p. 243). Assim, reitera esse analista, na geografia traçada a partir de um confronto ao mesmo tempo amigável e tenso de ipseidades (entre o EU e o Não-EU), “[...] a porta, os limiares, a soleira desempenham um papel fundamental. Esses locais mágicos devem ser tanto protegidos quanto violados" E nessa "singularidade do encontro único", como ele refere, instituem-se novas regras, sem que, no entanto, com elas seja barrado "[...] o conflito agônico, a transformação do dom em sacrifício" (SELIGMANNSILVA, 2005, p. 243).

Lembre-se ainda com Lang (2004, p. 20) de que a raiz host está presente em "hospedeiro" e em "hóstia" (primeiramente, a vítima oferecida em sacrifício, depois o alimento, o pão consagrado - o pão). Assim, em sua análise, "O Host, o hospedeiro é, ao mesmo tempo, o que alimenta, como o que serve de alimento". Por outro lado, na raiz host, está também a raiz de hoste, de inimigo. Isso explicaria que, "No interior de host há esse sentido antitético do familiar e íntimo e do estranho e estrangeiro". Num sentido lato do que nos diz Korstanje (2010), estariam em jogo os limites entre o estrangeirismo e o lar.

A diluição desse estado conflituoso requereria, pois, a experiência da descentração, do sair de si à procura do outro, experiência essa "[...] de contornos éticos e aberta à novidade, ao imprevisto, ao 'mistério' do Outro e à desmesura que excede o encontro com esse outro" (GONÇALVES E SOUSA, 2014, p. 164).

Na perspectiva levinasiana, conforme os mesmos autores, significaria deixar-se expor a uma relação em que o Eu passa a ser uma relação Eu-e-Tu, “[...] que não pode ser estabelecida na base de uma razão fria, mas através da vontade, paixão, razão e sentimento" (GONÇALVES E SOUSA, 2014, p. 163), ou, como bem ressalta Baptista (2005, p. 13), implicaria o estar perante uma situação extraordinária e paradoxal, em que “[...] o ponto de união, de identidade 
entre seres humanos, reside no fato de cada um ser sujeito de uma separação, [...] sujeito de uma soberania."

Numa outra leitura, tem-se a condição conflituosa da coexistência da bidimensionalidade do acolhimento como problema e como desejo (PERAZZOLO et al., 2014): condição, de um lado, acentuada pela barreira linguística; de outro, porém, abalada pelas marcas culturais do estrangeiro, que tonalizam sua atitude pelo respeito ao espaço do acolhedor, procurando não o violar, atendendo prontamente a solicitações de realização de tarefas, indo mesmo além do esperado (como pintar as paredes dos fundos da loja), instituindo, informalmente - ainda que não reconhecido e compartilhado em semelhante grau e forma, como poderia ser esperado um espaço interacional via uma linguagem que extrapola o domínio da língua. Essa maneira de ser e agir se mostra como uma tentativa do chinês de retribuir ao que estava recebendo independentemente do que se passava intimamente com seu anfitrião - e, de certo modo, numa mistura de vínculos espirituais do dar-receber-retribuir a que se refere Mauss (2003), de inaugurar outras/novas relações interpessoais.

Dois fatos, no entanto, vêm provocar fraturas mais profundas nas barreiras relacionais entre os protagonistas, na medida em que, por seu caráter fortuito ou inusitado, acabam por propiciar aprendizagens transformadoras da tessitura dos vínculos entre eles, matizadas pela experimentação do prazer e da afetividade: o primeiro, a intervenção do chinês salvando seu anfitrião de agressões físicas, mesmo após este tê-lo expulsado de sua casa por ver, nas peças acidentalmente "quebradas" pelo hóspede, romper-se e ter exposta parte de seu território interior; o segundo, o entrelaçamento de histórias de vida marcadas por situações trágicas que os aproximam, a partir do rompimento da barreira linguística propiciada pela atuação de um tradutor ocasional - o que vem ao encontro do pensamento de que "A palavra é uma espécie de ponte lançada entre mim e os outros.” (BAKHTIN, 1986, p. 113).

Tais fatos parece configurarem-se como elementos catalizadores de desdobramentos de uma nova narrativa, na qual se instaura uma nova sociodinâmica de acolhimento, em que se instala a disposição do acolher o outro dentro de si, na alternância dos papéis de acolhedor e acolhido (PERAZZOLO, SANTOS E PEREIRA, 2013). Em outras palavras: passa-se da quase surdez relacional, particularmente por parte do anfitrião, para a abertura à escuta do outro, destacando-se um novo lugar para o estrangeiro, um lugar em que “[...] suas demandas são consideradas, suas perspectivas refletidas" (SANTOS, PERAZZOLO E PEREIRA, 2014, p. 
53); em que se desconstrói a construção da mesmidade identitária pela construção da identidade do mesmo em permanente interação relacional com a alteridade (DUQUE, 2014). É nesse processo de "eleição intersubjectiva" (sic), conforme sugere Baptista (2008), que o encontro interpessoal é gerado como uma experiência de mútua e contínua autorização. Dessa nova relação de hospitalidade/acolhimento, resultam: geração de aprendizagens, ressignificações, transformações. Descobrem-se um ao outro, redescobrem-se a si próprios.

Poder-se-ia desde então perguntar: Romper com sua antiga cotidianidade e permitir-se a experiência de novas vivências relacionais em novos espaços (nelas incluídas as amorosas, antes contidas), não seria um sinalizador de aprendizagens, de transformações por que passa o comerciante argentino, propiciando alterações nos níveis de assimetria marcados pelas necessidades de acolhimento do chinês e por sua própria disposição para acolher?

Se em "hospitalidade" encontra-se a raiz per ou pit - que provém de pot, cujo significado é de "senhor", "mestre" (LANG, 2004), tais transformações poderiam estar "des"-velando a passagem do status de "senhor do hóspede" para "acolhedor e acolhido do/pelo hóspede", numa evolução de uma relação inicialmente assimétrica para uma relação simétrica.

$\mathrm{Na}$ assimetria, as relações são desiguais no que tange à necessidade de alguém (sujeitos/grupos) de ser acolhido, interpretado e atendido pelo outro e da disposição desse outro para acolher, no interior de si, aquele que necessita, metabolizando suas demandas e devolvendo-as de forma assimilável. [...] A condição desigual é marcada, efetivamente, pelo binômio “disposição - necessidade". [...] Já no contexto do acolhimento simétrico, o pressuposto é o de que prevaleça um padrão de igualdade em ambos os polos da relação, no que tange às demandas e condições de trocas geradoras de saberes. Nesse sentido, o outro [...] é um como eu e, ao mesmo tempo, diferente de mim, cujas mãos podem me levar a novos universos. Portanto, nesse caso, não há, a priori, dependência ou desequilíbrio de necessidades que precisam ser atendidas, mas um desejo compartilhado de acolher e ser acolhido, de sair de si e aprender. (PERAZZOLO, PEREIRA e SANTOS, 2014, p. 6).

Nesse contexto, assume um sentido particular a pintura de uma vaca deixada pelo chinês na parede dos fundos da loja, antes de despedir-se de seu acolhedor e ir ao encontro do parente que fora localizado. No gesto, tem-se instalada uma reconfiguração sígnica: ao mesmo objeto, em momentos diferentes, são conferidos valores e significações diversos. O animal, para o chinês, carregava a marca de ser causa de separação (morte de sua noiva); para o comerciante, apenas mais um objeto singular e bizarro de uma das notícias insólitas que colecionava sobre fatos inusitados, desprovido de quaisquer traços de afetividade. Quando descoberta a relação 
íntima entre os fatos, a vaca transforma-se em um dos elos da tessitura de novos laços que foram sendo construídos por e entre eles.

"A hospitalidade, portanto, se dá na relação com o outro, qualquer outro, pois todos os outros são estrangeiros ao eu." (SANTOS, PERAZZOLO E PEREIRA, 2014, p. 52); dá-se na relação com o estrangeiro, cuja chegada “[...] fratura, por vezes de forma desagradável e traumática, a sequência de instantes tendencialmente percepcionados numa lógica de continuidade", como nos chama a atenção Baptista (2005, p. 15), mas que, por outro lado, transforma o lugar da interrupção no cerne do processo de vinculação, de fortalecimento da relação interpessoal, de solidificação de laços sociais. Nas considerações de Selwyn, (2004), atos de hospitalidade consolidam relações, promovem-nas simbolicamente e também as transformam em novas estruturas de relação. "Para constituir o espaço de uma casa habitada e um lar, é preciso também uma abertura, uma porta e janelas, é preciso dar passagem ao estrangeiro. Não existe casa ou interioridade sem portas e sem janelas.", reflete Derrida (2003, p. 55).

\section{5. À Guisa de Considerações Finais}

Para encaminhar uma finalização destas reflexões, mostra-se interessante retomar o título que encima o trabalho: Uma narrativa na tela: um dos mundos possíveis para adentrar o universo conceitual da hospitalidade, e nele, particularmente, voltar o olhar sobre a expressão "um dos mundos possíveis", graficamente destacada pelo recurso da fonte itálica.

Como elemento de ancoragem do texto, possibilitando articulações temáticas e estruturais, factuais ou expressivas (GUIMARÃES, 1990), predições ou seleções na construção de vínculos informacionais, conceituais e de sentidos, o título, neste momento, encerra, numa leitura retroativa, o suposto teórico assumido concernente a relações entre ficção e realidade suposto esse que difere das concepções platônica ou aristotélica (nas quais a ficção deriva da realidade), considerado o entendimento dos mundos ficcionais como possíveis estados das coisas - tese de Dolezel, 1988, referida por Jeha (1993). O título encerra ainda o acolhimento ao suposto teórico mencionado pelo autor de que, valendo-se de canais semiósicos, o leitor/espectador pode transitar dos existentes reais para o mundo dos possíveis, apropriandose deles como fonte de experiência, de igual modo como integra e experimenta o mundo real.

É sob essa perspectiva que, na análise fílmica a que se procedeu, conversam, entrecruzam-se e permeiam-se fatos vivenciados na tela e/ou no mundo real, experiências afetivas, reflexivas e 
interpretativas situadas no universo das práticas de hospitalidade e das teorizações que sobre ela são construídas.

É por essa razão que a breve análise realizada permite reportar-nos à importância de pensar o encontro de subjetividades diferentes mas não indiferentes (BAPTISTA, 2005), com a superação, nos mais diversos espaços das relações cotidianas, de fronteiras simbólicas (DENCKER, 2013); a importância de dispor-se, nessas relações - como na convivência a que se viram compelidos o chinês e seu anfitrião - a

[...] uma espécie de apagamento das marcas específicas de pertencimento, de forma a atenuar os significados originais de certas condutas. Com isso, acontece um afastamento de significados das diferenças e se dá uma adesão a um conjunto de significados comuns que fundamentam as trocas sociais. Tal processo resulta na criação de uma legitimidade, diferente da original, em um processo naturalizante da tradição, que cria novas regras sacralizadas, que passam a orientar as ações dos indivíduos. (RODRIGUES, 1990, apud DENCKER, 2013, p. 7).

A análise permite igualmente reportarmo-nos à possibilidade de acolhida antes mesmo do próprio Rosto a ser acolhido (DERRIDA, 1998, apud MENEZES, 2008); a conversão daquilo que se doa em um verdadeiro ganho, pois que, segundo Caillé (2005) - a quem faz menção Duque (2014) -, é o donatário que atualiza o valor do dom. A hospitalidade “[...] revigora o saber ver e ser visto, o saber falar e ouvir como portas de entrada e, ao mesmo tempo, como ancoradouro da vida em conjunto." (SANTOS, OLIVEIRA E MARINHO, 2009, p. 18).

É, pois, no e pelo tecer dessa "trama" reflexiva, que emerge o convite a partilhar, com Farias (2014, p. 124-125), a compreensão de que são imaginários os mapas sobre os quais caminhamos, bem como de que nossa condição mais genuína não compreende fronteiras.

É possível festejar o encontro com o estrangeiro, gostar do encontro, desejálo, querê-lo [na medida em que] provoca, suspende o automatismo, introduz diferença, libera a vida; [...] recebe o estrangeiro como um ato de criação, como quem abre o mundo. [...] Sempre futura deve ser a ética do estrangeiro, porque o encontro nunca termina de começar. Porque o encontro é, ele mesmo, abertura - diz o autor.

O trânsito bidirecional entre existentes reais e mundos possíveis ou possíveis estados das coisas a que nos conduz Um Conto Chinês nos aponta para a possibilidade de trilharmos caminhos recíprocos na direção do outro e neles serem gerados novos saberes, transformações pessoais e novas amarras na construção de laços sociais. 


\section{Referências}

ARISTÓTELES. Poética. Madrid: Editorial Gredos. Edição trilíngue por Valentín García Yebra. 1974.

AUMONT, J.; MARIE, M. L'analyse des films. París: Nathan, 1988.

BAPTISTA, I. A hospitalidade e a eleição intersubjectiva: sobre o espírito que guarda os lugares. Revista Hospitalidade, Ano V, n. 2, p.5-14, 2008.

BAPTISTA, L. Para uma geografia de proximidade humana. Revista hospitalidade. vol.2, n.2, p. 13$22,2005$.

BAKHTIN, M. V. Marxismo e filosofia da linguagem. São Paulo: Hucitec, 1986.

BORRADORI, G. (Org.) Filosofia em tempo de terror. Diálogos com Habermas e Derrida. Rio de Janeiro: Jorge Zahar Editor. 2003.

BRIZUELA, M. Los procesos semiósicos en el teatro: análisis de las meninas y el sueño de la razón, de Antonio Buero Vallejo. Oviedo: Kassel - Edition Reichenberger, Universidad de Oviedo, 2000. Disponível em: <https://books.google.com.br/books?id=SmhkgU69tTIC\&pg=PA2\&lpg=PA2\&dq=proceso+semi\%C3 \%B3sico\&source=bl\&ots=SAhDS8VlMU\&sig=A0pbGU_UKJ3Ckua2Cd_zjy9FXuw\&hl=pt-

$\mathrm{BR} \& \mathrm{sa}=\mathrm{X} \& \mathrm{ved}=0 \mathrm{ahUKEwiIq} 4 \mathrm{mKqaTKAhUMHZAKHXPsAIUQ6AEIKTAB} \# \mathrm{v}=$ onepage $\& \mathrm{q}=$ proce so\%20semi\%C3\%B3sico\&f=false >. Acesso em: 04 jan. 2016.

CAMARGO, L.O.L. Hospitalidade sem sacrifício? O caso do receptivo turístico. Revista hospitalidade. Ano III, n. 2, p.11-28, 2006.

DENCKER, A. Hospitalidade e interação no mundo globalizado. Revista Rosa dos Ventos, V. 5, N.1), p. 4-14, jan-mar, 2013.

DERRIDA, J. Anne Dufourmantelle convida Jacques Derrida para falar da hospitalidade. São Paulo: Escuta, 2003.

DUQUE, J. M. Fragmentos para uma filosofia da hospitalidade. In: SANTOS, M.M.C. e BAPTISTA, I. (Orgs.) Laços sociais: por uma epistemologia da hospitalidade. Caxias do Sul/RS: Educs, 2014, p.149-160.

EPSTEIN, I. O signo. São Paulo: Ática (Série Princípios), 1990.

FARIAS, A. B. de. Filosofia da hospitalidade para uma futura ética do estrangeiro. In: SANTOS, M.M.C. e BAPTISTA, I. (Orgs.) Laços sociais: por uma epistemologia da hospitalidade. Caxias do Sul/RS: Educs, 2014, p $115-126$.

GONÇALVES, J. L. A., e Sousa, J. E. P. de. Hospitalidade: experiências de dádiva que desenvolvem o self e renovam o laço social. In: SANTOS, M.M.C. e BAPTISTA, I. (Orgs.) Laços sociais: por uma epistemologia da hospitalidade. Caxias do Sul/RS: Educs, 2014, p. 161-178.

GRASSI, M. Transpor a Soleira. In: MONTANDON, A. O livro da hospitalidade: acolhida do estrangeiro na história e nas culturas. São Paulo: Editora Senac, 2011, p.45-53.

GUIMARÃES, E. A articulação do texto. São Paulo: Ática (Série Princípios), 1990.

JEHA, J. Mimese e mundos possíveis. Signótica, v. 5, p. 79-90. 1993. Disponível em: <http://www.revistas.ufg.br/index.php/sig/article/viewFile/7354/5219>. Acesso em: 03 mai. 2015.

KORSTANJE, M. Turismo. Las formas elementales de la hospitalidade. Revista brasileira de pesquisa em turismo, vol.4, n.2, p. $86-111,2010$. 
LANG, C. A tradição da hospitalidade, o sacrifício da hospitalidade. Protestantismo em revista, v. 3, p. 19-27, jan.-abr. 2004.

MAUSS, M. Sociologia e antropologia. São Paulo: Cosac \& Naify, 2002.

MENEZES, M. M. A Educação no Desejo: A linguagem e a ética em Emmanuel Lévinas. 31. ed. Reunião anual da ANPED. Caxambu, MG. GT 17, 2008. Disponível em: <http://31 reuniao.anped.org.br/1trabalho/GT17-4892--Int.pdf>. Acesso em: 10 jan. 2016.

MONTADON, A. Espelhos da hospitalidade. In: MONTADON, A. (Ed.). O livro da hospitalidade. São Paulo: SENAC, 2011, p. 31-37 (Prefácio).

PERAZZOLO, O. A., SANTOS, M. M. C., PEREIRA, S. Dimensión relacional de la acogida. Estudios y perspectivas en turismo, v. 22, p. 138-153, 2013.

PERAZZOLO, O. A.; PEREIRA, S.; SANTOS, M. M. C.; FERREIRA, L. T. Acolhimento e desenvolvimento socioturístico: para uma psicopedagogia do laço social. In: SANTOS, M.M.C. e BAPTISTA, I. (Orgs.) Laços sociais: por uma epistemologia da hospitalidade. Caxias do Sul/RS: Educs, 2014, p. 65-82.

PERAZZOLO, O. A.; PEREIRA, S.; SANTOS, M. M. C. Sincronia e Simetria: proposições tipológicas para o acolhimento. In: Anais (s.p.). XI Seminário Nacional de Pesquisa em Turismo ANPTUR. Universidade Estadual do Ceará - Fortaleza/CE, 2014.

PERAZZOLO, O.A.; PEREIRA, S.; LEONCIO, B.; SOLDATELLI, S.B. Hospitalidade e hostilidade: reflexões sobre fronteiras entre aceitação e rejeição. In: Anais (s.p.) VIII Seminário de Pesquisa em Turismo do Mercosul e I Hospitalidade em Colóquio. Caxias do Sul, Universidade de Caxias do Sul/ Caxias do Sul/RS, 2015.

PLATÃO. s.d. A república. Disponível em: < http://www.livros-digitais.com/platao/a-republica/>. Acesso em: 13 jan. 2016.

SANTOS, M. M. C. dos; PERAZZOLO, O. A.; PEREIRA, S. Hospitalidade numa perspectiva coletiva: O corpo coletivo acolhedor. In: SANTOS, M.M.C.; BAPTISTA, I. (Orgs.) Laços sociais: por uma epistemologia da hospitalidade. Caxias do Sul/RS: Educs, 2014, p. 49-63.

SANTOS, M.M.C. dos; OLIVEIRA, A.C.R.M. de; MARINHO, M.F. Pedagogia da hospitalidade: da formação à atuação profissionais em turismo. In: Anais (s.p.). XI Seminário Internacional de Turismo. Universidade Positivo, Curitiba/PR, 2009.

SELIGMANN-SILVA, M. O local da diferença: ensaios sobre memória, arte, literatura e tradução. São Paulo: Ed. 34, 2005.

SELWYN, Tom. Uma antropologia da hospitalidade. In: LASHLEY, C.; MORRISON, A. Em busca da hospitalidade: perspectivas para um mundo globalizado. Barueri-SP: Manole, 2004. p. 25-52.

SOHEL, P. Images du récit. Québec, Presses Universitaires du Québec, 2007.

\section{Recebido em: 03/07/2016 (1 ${ }^{\text {a }}$ versão) $27 / 06 / 2016$ ( $2^{\text {a }}$ versão)}

Aprovado em: 12/07/2016 